\title{
The impact of garlic on lipid parameters: a systematic review and meta-analysis
}

\author{
Kurt M. Reinhart ${ }^{1,2}$, Ripple Talati ${ }^{1,2}$, C. Michael White ${ }^{1,2}$ and Craig I. Coleman ${ }^{1,2 *}$ \\ ${ }^{1}$ Department of Pharmacy Practice, University of Connecticut School of Pharmacy, Storrs, CT, USA \\ ${ }^{2}$ Department of Drug Information at Hartford Hospital, Hartford, CT, USA
}

\begin{abstract}
In order to determine the impact of garlic on total cholesterol (TC), TAG levels, as well as LDL and HDL, and establish if any variables have an impact on the magnitude of this effect, a metaanalysis was conducted. A systematic literature search of MEDLINE, CINAHL and the Cochrane Database from the earliest possible date through to November 2007 was conducted to identify randomised, placebo-controlled trials of garlic that reported effects on TC, TAG concentrations, LDL or HDL. The weighted mean difference of the change from baseline (with $95 \% \mathrm{CI}$ ) was calculated as the difference between the means in the garlic groups and the control groups using a random-effects model. Subgroup and sensitivity analyses were performed to determine the effects on type, brand and duration of garlic therapy as well as baseline TC and TAG levels, the use of dietary modification, and study quality on the meta-analysis's conclusions. Twenty-nine trials were included in the analysis. Upon meta-analysis garlic was found to significantly reduce TC $(-0.19 ; 95 \% \mathrm{CI}-0.33,-0.06 \mathrm{mmol} / \mathrm{l})$ and TAG $(-0.11 ; 95 \% \mathrm{CI}-0.19,-0.06 \mathrm{mmol} / \mathrm{l})$ but exhibited no significant effect on LDL or HDL. There was a moderate degree of statistical heterogeneity for the TC and TAG analyses. Garlic reduces TC to a modest extent, an effect driven mostly by the modest reductions in TAG, without appreciable LDL lowering or HDL elevation. Higher baseline line TC levels and the use of dietary modification may alter the effect of garlic on these parameters. Future studies should be conducted evaluating the impact of adjunctive garlic therapy with fibrates or statins on TAG concentrations.
\end{abstract}

Garlic: Preventive medicine: Dyslipidaemias: Allium sativum: Meta-analyses

Total cholesterol (TC) measurements are comprised of three different types of lipoproteins: LDL, VLDL and HDL. LDL and VLDL are apoB100-containing particles and are both positively associated with atherosclerosis while HDL is thought to be cardioprotective in higher concentrations. In addition to promoting atherosclerosis, markedly elevated TAG increases the risk of developing pancreatitis and lipomas. While several pharmacological agents are available to reduce LDL (statins, bile acid sequestrants, niacin, ezetimibe) and TAG (statins, fibric acid derivatives, niacin), not all patients can achieve current National Cholesterol Education Program Adult Treatment Panel III goals $^{(1)}$ with available pharmacotherapy while others have trouble tolerating therapy or may seek more natural therapies. As such, patients and clinicians are interested in nutraceuticals that can potentially modulate plasma lipids.

Garlic (Allium sativum) is a nutraceutical touted to lower cholesterol. Previous meta-analyses have demonstrated a decrease in TC although newer meta-analyses have showed smaller reductions with the incorporation of newer studies $^{(2-5)}$. As such, with additional studies evaluating the lipid-modulatory effects of garlic being published, it will be important to discern whether the literature still supports garlic's ability to reduce TC. Since it is the individual constituents of TC, more so than TC itself, which is more prognostic for the risk of CHD, we will also determine the impact of garlic on LDL, HDL and TAG.

\section{Methods}

Data sources

We conducted a systematic literature search of MEDLINE, CINAHL and the Cochrane Database from the earliest possible date through to November 2007. We used the following medical subject headings $(\mathrm{MeSH})$ and keywords: 'garlic', 'Allium sativum' or 'allicin'. Results were limited to randomised clinical trials in human subjects. A manual

Abbreviation: TC, total cholesterol.

* Corresponding author: Dr Craig I. Coleman, fax +1 860545 2277, email ccolema@ harthosp.org 
search of references from reports of clinical trials, review articles and previous meta-analyses was performed to identify additional relevant studies.

\section{Study selection}

According to pre-specified criteria, trials must have utilised garlic, reported TC, LDL, HDL or TAG endpoints and have been published in English or German to be evaluated for exclusion criteria. Studies were excluded if they were not randomised, placebo-controlled and double-blind, combined garlic with other nutraceuticals or products with lipid-altering effects, or lacked sufficient data to allow for statistical pooling. Both parallel and cross-over trials were eligible for inclusion. If cross-over trials did not include a washout period, they were still included in the analysis if the follow-up after the intervention and control was each at least 3 weeks, at which time lipid values would be considered stable $^{(6)}$. Two authors (K. M. R. and R. T.) independently reviewed abstracts or full publications of all identified citations to evaluate them for inclusion and exclusion criteria with disagreement resolved by discussion or evaluation by other investigators (C. M. W. and C. I. C.).

\section{Data abstraction}

Two investigators (K. M. R., R. T.) utilised a standardised data abstraction tool and independently abstracted data with disagreement resolved by discussion. The following information was sought from each trial: author identification, year of publication, study design, study population, sample size, type of garlic used, brand of garlic used, duration of treatment, required $\mathrm{TC}$ and $\mathrm{TAG}$ levels at baseline, Jadad score for quality assessment ${ }^{(7)}$ and whether or not dietary counselling was given or if patients were required to maintain a low-fat-low-cholesterol diet. Study endpoint data extracted included baseline and final TC, LDL, HDL and TAG concentrations and measures of variance for these variables at these time points. Any discrepancies in extracted data between reviewers were resolved through discussion. For TC, LDL and HDL values reported in $\mathrm{mg} / \mathrm{dl}$, the corresponding $\mathrm{mmol} / \mathrm{l}$ value was calculated by multiplying the value by 0.0259 . Any TAG levels given in $\mathrm{mg} / \mathrm{dl}$ were multiplied by 0.0113 to derive the $\mathrm{mmol} / \mathrm{l}$ value.

\section{Data synthesis and analysis}

The mean change in lipid parameters from baseline was treated as a continuous variable and the weighted mean difference was calculated as the difference between the means in the garlic and control groups. A random-effects model was used in calculating the weighted mean difference and its $95 \%$ CI. For parallel trials, net changes in each study parameter were calculated as the difference (garlic minus control) of the changes (follow-up minus baseline) in the mean values. For cross-over trials, net changes were calculated as the mean difference in values at the end of the garlic and control periods. If variances for net changes were not reported directly, they were calculated from CI, $P$ values or individual variances for intervention and placebo groups/periods. For parallel trials in which variance for paired differences were reported separately for each group, we calculated a pooled variance for net change by standard methods ${ }^{(8)}$. When the variance for paired differences was not reported, we calculated it from variances at baseline and at the end of follow-up using a correlation coefficient of 0.4 as suggested by a previous garlic meta-analysis ${ }^{(2)}$. Weighted mean differences and 95\% CI were calculated using StatsDirect (version 2.6.2; StatsDirect Ltd, Sale, Cheshire, UK) using a random-effects model.

Many sensitivity and subgroup analyses were conducted. Studies of poorer methodological quality may exhibit inaccurate treatment effect. Limiting the meta-analysis to only higher-quality trials may result in increased internal validity but could reduce its external validity (applicability). As such, we conducted a sensitivity analysis excluding studies of poorer methodological quality (Jadad score less than 3). Since the exact time course of garlic's proposed lipid-lowering effects is not known, studies of longer duration might have yielded a greater change in lipid parameters. As such, we examined studies of 12 weeks or less in duration and studies lasting for longer than 12 weeks separately. Since there are several manufacturers of garlic products and garlic is not regulated by the Food and Drug Administration, there is likely to be variability in the quality of products between companies. Therefore, we performed subgroup analysis whereby we excluded all brands except $\mathrm{Kwai}^{\circledR}$ (Lichtwer pharma GmbH, Berlin, Germany), the most studied brand of garlic in the medical literature. Likewise, there exist different preparations of garlic which can potentially deliver differing amounts of potentially active constituents of garlic to the bloodstream and so we performed subgroup analyses based on the type of product including garlic powder, garlic oil and aged extract preparations. Patients with larger TC concentrations might be more amenable to lipid alterations than those with nearnormal baseline TC levels. However, subjects with very high TC might have genetic disorders that preclude lipidmodulating therapy from being fully effective. As such, we performed subgroup analysis where we calculated garlic's effects based on the mean baseline TC of the patients being studied. Studies with one or more treatment groups exhibiting a baseline cholesterol $<6.48 \mathrm{mmol} / 1(250 \mathrm{mg} / \mathrm{dl}$; $2500 \mathrm{mg} / \mathrm{l}$ ) were analysed separately from the studies where the mean value was $\geq 6.48 \mathrm{mmol} / \mathrm{l}$; studies with one or more treatment groups exhibiting baseline TAG $<1.7 \mathrm{mmol} / \mathrm{l}$ $(150 \mathrm{mg} / \mathrm{dl} ; 1500 \mathrm{mg} / \mathrm{l})$ were analysed separately from the studies where the mean value was $\geq 1.7 \mathrm{mmol} / \mathrm{l}$. It is possible that the effect of a lipid modulator could be dependent on the dietary intake of fats and cholesterol. Studies with dietary counselling or dietary restrictions in addition to garlic therapy might yield different results from studies without such counselling or restrictions. As such, we performed subgroup analyses whereby we evaluated studies which required dietary modification or counselled patients on lowfat and low-cholesterol diets independently from the studies where this was not part of the methodology. For each main analysis, outlier trials, defined as those whose $95 \%$ CI did not cross the pooled effect, were removed and analysis was performed to evaluate their impact on the observed effects.

Statistical heterogeneity was calculated using the $I^{2}$ statistic. An $I^{2}$ of greater than $25 \%$ was considered to be 
representative of a moderate degree of statistical heterogeneity and a value greater than $75 \%$ was considered a high degree of statistical heterogeneity. Funnel plots and Egger's weighted statistic were used to assess for publication bias. Duval and Tweedie's trim and fill plots were used to determine how any publication bias would affect the results. Trim and fill plots were created using MIX software (version 1.54; freely accessible at http://www. mix-for-meta-analysis.info).

\section{Results}

The initial search yielded 2958 results and Fig. 1 describes how many studies were excluded, for what reasons and how many studies were ultimately included. In brief, 172 citations represented controlled trials in human subjects published in English or German, and forty-nine trials reported one or more of the lipid endpoints. Twenty studies met exclusion criteria, thus twenty-nine studies were eligible for analysis ${ }^{(9-37)}$. Reasons for exclusion included studies that were not randomised ${ }^{(38-40)}$, not placebocontrolled or double blind ${ }^{(41-48)}$, garlic not given as a monopreparation $^{(49)}$, concurrent use of medications known to increase serum cholesterol ${ }^{(50)}$ or studies lacking enough data for statistical pooling ${ }^{(51-56)}$. One study reported results of selected patients from another trial and was therefore excluded $^{(57)}$. Of note, in one included study ${ }^{(30)}$, one investigation centre gave all patients garlic powder in a non-randomised fashion and therefore data for these patients were not included in the meta-analysis. Another study by Rahmani et al. had three active treatment arms of increasing doses of a garlic powder preparation (Garlet; Kowsar Pharmaceutical Co., Tehran, Iran) ${ }^{(22)}$. While this study did not report the allicin content of this preparation, another study using Garlet reported that each tablet contained $1 \mathrm{mg}$ allicin ${ }^{(36)}$. Therefore, only the $1200 \mathrm{mg}$ garlic powder treatment arm was included as it provided an amount of allicin closest to the studies using the Kwai ${ }^{\circledR}$

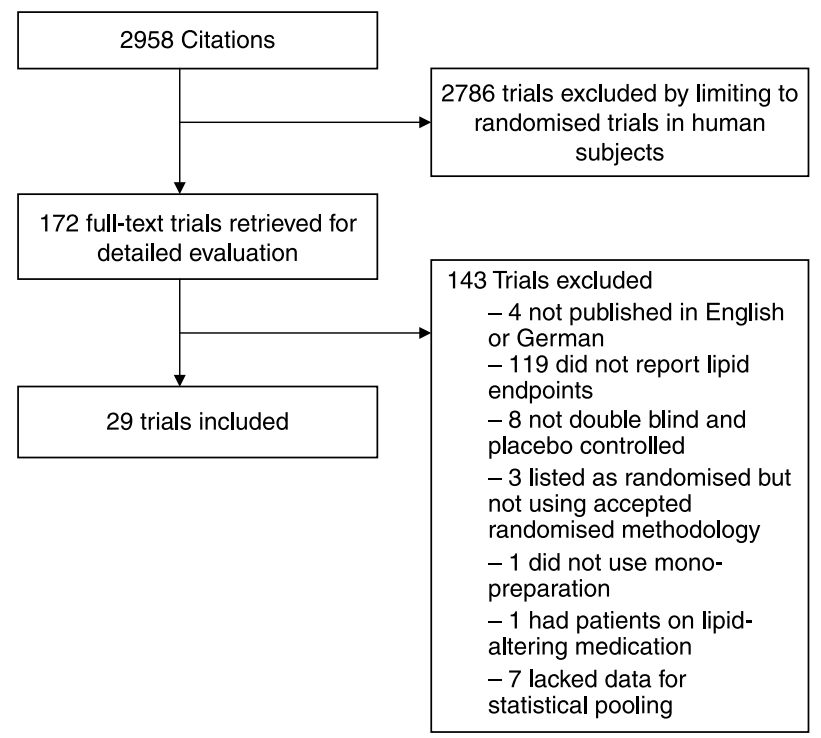

Fig. 1. Flow diagram of trial identification, inclusion and exclusion. brand garlic powder (3 mg allicin for Garlet, $1.8 \mathrm{mg}$ allicin for $\left.\mathrm{Kwa} i^{\circledR}\right)$. Seven studies utilised a cross-over design. In general their design and washout period varied dramatically, ranging from 0 to 4 weeks of washout. We therefore conducted sensitivity analysis to evaluate their impact $^{(31-37)}$. Finally, in three of the included cross-over studies, data were presented in two mutually exclusive groups of patients and therefore each study was broken down into two parts named study (a) and study (b) ${ }^{(34,35,37)}$.

Of the twenty-nine included studies ${ }^{(9-37)}$, twenty-eight

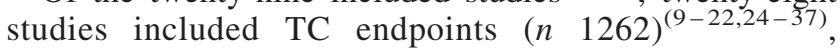
twenty-one studies included LDL endpoints $(n 756)^{(9,12-15,17,19-22,24,26,27,29-36)}$, twenty-four studies

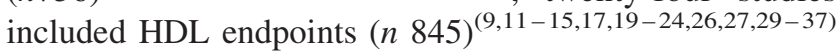
and twenty-eight studies included TAG endpoints (n 1220) $^{(9-15,17-37)}$. Characteristics of the included trials are given in Table 1.

The results of the meta-analysis of trials evaluating TC are displayed in Fig. 2. Overall, garlic was found to significantly reduce the levels of TC by 0.19 (95\% CI $-0.33,-0.06) \mathrm{mmol} / 1(7.35 \mathrm{mg} / \mathrm{dl} ; 73.5 \mathrm{mg} / \mathrm{l})$ compared with placebo. There was a moderate amount of statistical heterogeneity among the studies $\left(I^{2} 64.3 \%\right)$ and four studies reported $95 \%$ CI that did not cross the pooled effect. When these outlier trials were excluded, TC was reduced by a more moderate 0.12 (95\% CI $-0.21,-0.04) \mathrm{mmol} / \mathrm{l}$ but still to a significant degree, and statistical heterogeneity was reduced $\left(I^{2} 2.9 \%\right)$. The Egger's weighted statistic $(P=0.37)$ suggested that publication bias was unlikely and the trim and fill plot imputed no additional studies minimizing the possibility that publication bias had an impact on results. When cross-over studies were excluded from the analysis, the decrease in TC was slightly greater at 0.27 (95\% CI - 0.45, - 0.09) mmol/1.

The results of garlic's effects on TAG are displayed in Fig. 3. Garlic significantly lowered TAG levels by $0 \cdot 11$ (95\% CI -0.19, - 0.03) mmol/l (9.7 mg/dl; $97 \mathrm{mg} / \mathrm{l})$ compared with placebo. There was a moderate degree of statistical heterogeneity among the studies ( $\left.I^{2} 26.7 \%\right)$. Visual inspection elucidated three studies which had $95 \%$ CI that did not cross the pooled effect. When these outlier trials were excluded from analysis, TAG were reduced by $0.11(95 \%$ CI $-0.17,-0.04) \mathrm{mmol} / \mathrm{l}$, the same effect observed with inclusion of the outlier studies. Again statistical heterogeneity was reduced $\left(I^{2} 0 \%\right)$. The Egger's weighted statistic $(P=0 \cdot 87)$ suggested that publication bias was unlikely and trim and fill plot imputed no additional studies minimising the possibility that publication bias had an impact on results. When cross-over studies were excluded from the analysis, the decrease in TAG was 0.15 (95\% CI -0.26, - 0.03) $\mathrm{mmol} / \mathrm{l}$, similar to the base analysis.

Garlic did not exhibit significant effects on either LDL or HDL concentrations, although very modest qualitative reductions in LDL and elevations in HDL were noted (Table 2). A minor degree of statistical heterogeneity was calculated among studies used for these endpoints $\left(I^{2}<24 \%\right.$ for both). A low likelihood of publication bias was noted (Egger's weighted statistic, $P>0 \cdot 18$ for both). 
Table 1. Characteristics of included studies

\begin{tabular}{|c|c|c|c|c|c|c|c|c|c|}
\hline Study & Jadad score & $\begin{array}{c}\text { Proper } \\
\text { concealment }\end{array}$ & $\begin{array}{c}\text { Subjects } \\
\text { (garlic/placebo) }\end{array}$ & Type & Brand & Duration & $\begin{array}{l}\text { Baseline } \\
\text { TC }(\mathrm{mmol} / \mathrm{l})\end{array}$ & $\begin{array}{c}\text { Baseline } \\
\text { TAG (mmol/l) }\end{array}$ & Diet modification \\
\hline Adler \& Holub (1997) ${ }^{(9)}$ & 4 & Yes & $12 / 11$ & GP & $\mathrm{Kwai}^{\circledR}$ & 12 weeks & $6 \cdot 48$ & 1.95 & No \\
\hline Auer et al. $(1990)^{(10)^{\prime}}$ & 2 & No & $24 / 23$ & GP & $\mathrm{Kwai}^{\circledR}$ & 12 weeks & $6 \cdot 79$ & 1.99 & No \\
\hline Berthold et al. (1998) ${ }^{(32)}$ & 4 & Yes & $25 / 25$ & GO & Tegra & 12 weeks & 7.53 & 1.45 & No \\
\hline Bordia $(1981)^{(11)}$ & 1 & No & $33 / 29$ & GO & None & 10 months & 7.25 & 1.94 & No \\
\hline Budoff et al. (2004) ${ }^{(12)}$ & 3 & Yes & $9 / 10$ & AGE & Kyolic $^{\circledR}$ & 12 months & 4.56 & 1.50 & Yes \\
\hline Isaacsohn et al. (1998) ${ }^{(13)}$ & 4 & Yes & $28 / 22$ & GP & $\mathrm{Kwai}^{\circledR}$ & 12 weeks & $6 \cdot 48$ & 1.81 & Yes \\
\hline Jain et al. $(1993)^{(14)}$ & 3 & Yes & $20 / 22$ & GP & $\mathrm{Kwai}^{\circledR}$ & 12 weeks & $6 \cdot 40$ & 1.71 & No \\
\hline Kannar et al. $(2001)^{(15)}$ & 3 & Yes & $20 / 23$ & GP & None & 12 weeks & 7.51 & 2.00 & Yes \\
\hline Kiesewetter et al. (1993) ${ }^{(16)}$ & 3 & Yes & $32 / 32$ & GP & $\mathrm{Kwai}^{(\circledast)}$ & 12 weeks & $6 \cdot 84$ & Unknown & No \\
\hline Macan et al. $(2006)^{(17)}$ & 3 & Yes & $22 / 26$ & AGE & Kyolic $^{\circledR}$ & 12 weeks & 4.77 & 2.07 & No \\
\hline Mader et al. $(1990)^{(18)}$ & 5 & Yes & $111 / 110$ & GP & $\mathrm{Kwai}^{\circledR}$ & 4 months & 6.79 & 2.45 & No \\
\hline McCrindle et al. $(1998)^{(19)}$ & 5 & Yes & $15 / 15$ & GP & $\mathrm{Kwai}^{\circledR}$ & 8 weeks & $6 \cdot 66$ & 1.14 & Yes \\
\hline Neil et al. $(1996)^{(20)}$ & 5 & Yes & $57 / 58$ & GP & $\mathrm{Kwai}^{\circledR}$ & 6 months & 6.97 & 1.71 & Yes \\
\hline Peleg et al. (2003) & 3 & Yes & $13 / 20$ & GP & Inodiel & 16 weeks & $6 \cdot 81$ & 1.92 & Yes \\
\hline Phelps \& Harris (1993) ${ }^{(31)}$ & 4 & Yes & $10 / 10$ & GP & $\mathrm{Kwai}^{\circledR}$ & 2 weeks & 4.53 & 0.87 & No \\
\hline Plengvidhya et al. (1988) (a) ${ }^{(37)}$ & 3 & Yes & $16 / 16$ & SDL & None & 8 weeks & 7.63 & 4.47 & Yes \\
\hline Plengvidhya et al. (1988) $(\mathrm{b})^{(37)}$ & 3 & Yes & $14 / 14$ & SDL & None & 8 weeks & $6 \cdot 88$ & 3.55 & Yes \\
\hline Rahmani et al. (1999)(22) & 2 & Yes & $30 / 22$ & GP & Garlet & 12 weeks & $6 \cdot 92$ & $2 \cdot 69$ & No \\
\hline Rotzsch et al. (1992) ${ }^{(23)}$ & 4 & Yes & $12 / 12$ & GP & $\mathrm{Kwai}^{\circledR}$ & 6 weeks & Unknown & 1.58 & No \\
\hline Santos \& Grünwald (1993) ${ }^{(24)}$ & 3 & Yes & $25 / 27$ & GP & $\mathrm{Kwai}^{\circledR}$ & 6 months & 6.94 & 1.65 & Yes \\
\hline Saradeth et al. (1994) & 4 & Yes & $31 / 37$ & GP & $\mathrm{Kwai}^{\circledR}$ & 15 weeks & $5 \cdot 62$ & 1.19 & No \\
\hline Satitvipawee et al. (2003) ${ }^{(26)}$ & 4 & Yes & $70 / 76$ & GE & None & 12 weeks & $6 \cdot 66$ & 1.19 & Yes \\
\hline Simons et al. $(1994)^{(33)}$ & 4 & Yes & $28 / 28$ & GP & $\mathrm{Kwai}^{\circledR}$ & 12 weeks & 6.72 & 1.53 & Yes \\
\hline Steiner et al. (1996) (a) ${ }^{(34)}$ & 4 & Yes & $17 / 17$ & AGE & None & 26 weeks & $6 \cdot 30$ & 2.44 & Yes \\
\hline Steiner et al. (1996) (b) & 4 & Yes & $24 / 24$ & AGE & None & 17 weeks & $6 \cdot 30$ & $2 \cdot 44$ & Yes \\
\hline Superko \& Krauss $(2000)^{(27)}$ & 2 & Yes & $25 / 25$ & GP & $\mathrm{Kwai}^{\circledR}$ & 12 weeks & 6.19 & 1.45 & Yes \\
\hline Tanamai et al. (2004) (a) ${ }^{(35)}$ & 4 & Yes & $45 / 45$ & GE & None & 13 weeks & 7.34 & 1.74 & Yes \\
\hline Tanamai et al. (2004) (b) ${ }^{(35)}$ & 4 & Yes & $55 / 55$ & GE & None & 13 weeks & 7.34 & 1.45 & Yes \\
\hline Vorberg \& Schneider (1990) $)^{(28)}$ & 3 & Yes & $20 / 20$ & GP & $\mathrm{Kwai}^{(\circledast)}$ & 16 weeks & 7.49 & $2 \cdot 18$ & No \\
\hline Williams et al. (2005) & 4 & Yes & $15 / 15$ & AGE & Kyolic & 2 weeks & 4.40 & 1.30 & No \\
\hline Zhang et al. $(2000)^{(29)}$ & 3 & Yes & $14 / 13$ & $\mathrm{GO}$ & Cardiomax & 16 weeks & 4.61 & 0.62 & No \\
\hline Zhang et al. (2001) ${ }^{(30)}$ & 3 & Yes & $19 / 21$ & GO & Cardiomax & 11 weeks & 4.82 & 0.96 & No \\
\hline
\end{tabular}

TC, total cholesterol; GP, garlic powder; GO, garlic oil; AGE, aged garlic extract; SDL, spray-dried garlic; GE, garlic extract. 


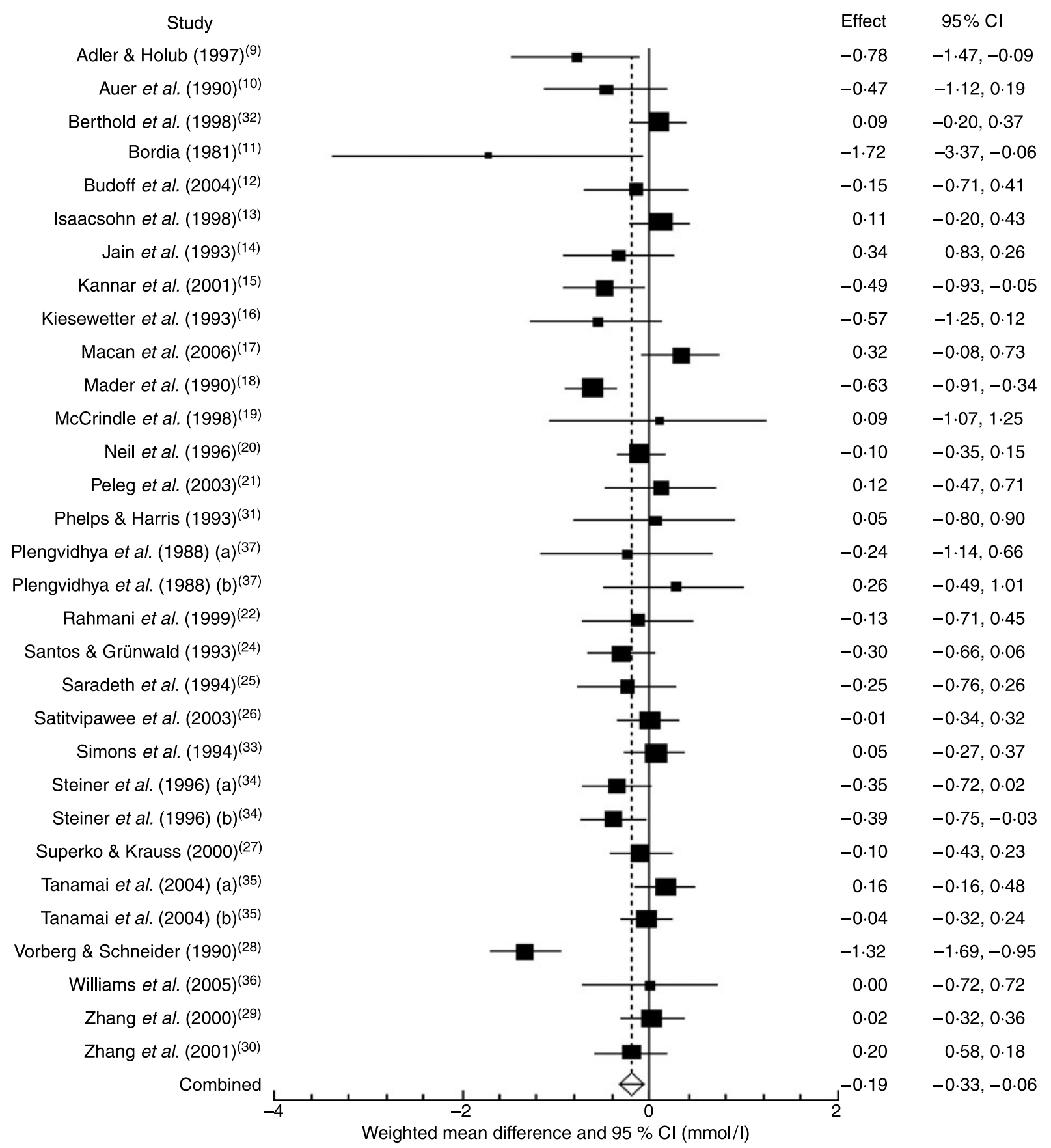

Fig. 2. Forest plot results of total cholesterol meta-analyses. Impact of garlic on total cholesterol as compared with placebo (mmol/l). (-), No effect of garlic on total cholesterol compared with placebo. Trials to the left of this show the further reductions in total cholesterol over and above that seen with placebo while trials to the right show the opposite effect. (- - -), Combined effect. The $I^{2}$ value for statistical heterogeneity was $64 \%$.

Several subgroup analyses found different magnitudes of effect with garlic therapy $v$. placebo (Table 3). Garlic's effect on TC was found to be greater in studies of 12 weeks or longer and with garlic powder, Kwai ${ }^{\circledR}$, higher baseline TAG levels, and when diet control was not used. Garlic's effect on TAG was greater in studies of lower Jadad score, and when diet control was not used. No large differences in effects on LDL or HDL were noted for any subgroup analyses.

\section{Discussion}

The 0.19 and $0.11 \mathrm{mmol} / \mathrm{l}$ reductions in $\mathrm{TC}$ and TAG reductions in the present meta-analysis were modest in size but achieved statistical significance. This is far less than prescription products such as statins (TC reductions of 35$55 \%$ and TAG reductions of up to $28 \%)^{(58)}$, niacin (TC reductions of $30 \%$ and TAG reductions of $55 \%)^{(59)}$ and fibrates (TC reductions of $10 \%$, TAG reductions of 


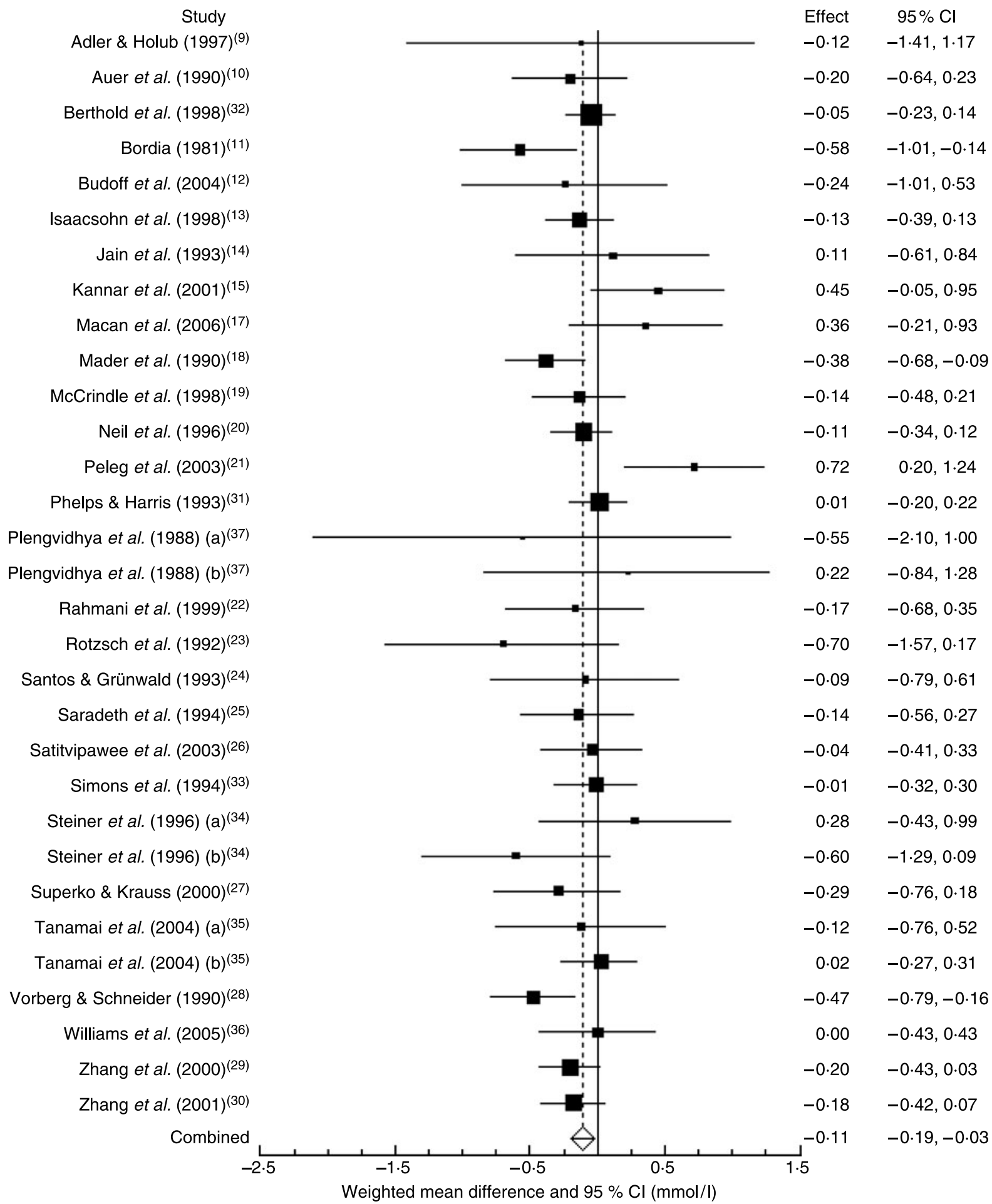

Fig. 3. Forest plot results of TAG meta-analyses. Impact of garlic on TAG as compared with placebo (mmol/l). (-), No effect of garlic on TAG compared with placebo. Trials to the left of this show the further reductions in TAG over and above that seen with placebo while trials to the right show the opposite effect. (-- -), Combined effect. The $I^{2}$ value for statistical heterogeneity was $27 \%$.

$45 \%)^{(59)}$. To compare, the effect of garlic observed in this analysis would equate to a $4 \%$ reduction in TC in a patient with a baseline TC of $5 \mathrm{mmol} / \mathrm{l}$. A patient with a baseline TAG of $2 \mathrm{mmol} / \mathrm{l}$ would have a $22 \%$ reduction in TAG with garlic. While LDL was qualitatively reduced and HDL elevated with garlic therapy, these effects were very small $(-0.05 \mathrm{mmol} / \mathrm{l}$ and $+0.025 \mathrm{mmol} / \mathrm{l}$, respectively) and $\mathrm{did}$ not achieve statistical or clinical significance.

While the TC reduction in the present study was less than the $0.41 \mathrm{mmol} / 1$ reduction in the previous meta-analysis 
Table 2. Main results of the meta-analyses

(Effect sizes and 95\% confidence intervals)

\begin{tabular}{lcccc}
\hline & Effect size $(\mathrm{mmol} / \mathrm{l})$ & $95 \% \mathrm{Cl}(\mathrm{mmol} / \mathrm{l})$ & $I^{2}(\%)$ & Egger bias \\
\hline Total cholesterol & -0.19 & $-0.33,-0.06$ & 64 & $P=0.38$ \\
LDL & -0.059 & $-0.151,0.032$ & 24 & $P=0.18$ \\
HDL & 0.025 & $-0.001,0.051$ & 9.6 & $P=0.60$ \\
TAG & -0.11 & $-0.19,-0.03$ & 26.7 & $P=0.87$ \\
\hline
\end{tabular}

by Stevinson et al. ${ }^{(2)}$, we allowed inclusion of studies that enrolled subjects without having hyperlipidaemia. We did this because the product is touted for general heart health promotion and including a greater number of trials increases the power of the meta-analysis to show a difference if one truly exists. We, however, did conduct subgroup analysis of studies with a patient population exhibiting hypercholesterolaemia. The reduction in TC in our hypercholesterolaemic subgroup $(-0.24 \mathrm{mmol} / \mathrm{l})$ was closer to that of Stevinson et al. ${ }^{(2)}$. The smaller effect in our analysis could be due to the inclusion of newer studies exhibiting a more modest effect. Like Stevinson et al. ${ }^{(2)}$, our analysis only included randomised, double-blind and placebo-controlled trials.

An important finding of our meta-analysis was that garlic reduced TC concentrations modestly with little impact on the LDL and HDL component of TC. It is possible that the reductions in the VLDL component of TAG may have provided the majority of the TC reductions seen in our meta-analysis. This is supported by a qualitative analysis that we conducted which was limited to the four trials that provided TC, LDL, HDL and TAG concentration data. In this qualitative analysis, the TC was decreased by 0.05 and TAG was decreased by $0.08 \mathrm{mmol} / \mathrm{l}$.

We believe that garlic's TAG effects are important because even though they were modest in size, they did not result in the elevation of LDL-cholesterol-like drugs such as gemfibrozil. Garlic has been compared head to head with bezafibrate and similar reductions in TAG as well as other lipid parameters were observed ${ }^{(60)}$. In this study, ninety-eight patients were randomised to garlic (given as $900 \mathrm{mg} \mathrm{Kwai}{ }^{\circledR}$ ) or $600 \mathrm{mg}$ bezafibrate for 12 weeks and lipid parameters were evaluated. Both bezafibrate and garlic significantly reduced TAG by roughly $0.85 \mathrm{mmol} / \mathrm{l}$ $(750 \mathrm{mg} / \mathrm{l})$ and $0.81 \mathrm{mmol} / 1(720 \mathrm{mg} / \mathrm{l})$ respectively (standard deviations not reported) without raising LDL. Bezafibrate did, however, trend towards lowering TAG more than garlic when analysed in patients with baseline TAG greater than $2.8 \mathrm{mmol} / \mathrm{l}$ (42 v. $29 \%$ respectively). While we did not include this study in our meta-analysis as it was not placebo controlled, this trial was in a population with hypertriacylglycerolaemia and found much more robust $\mathrm{TAG}$ reductions than in our meta-analysis. If garlic can reduce TAG in patients with elevated TAG concentrations without elevating LDL and can work synergistically with fibrates or niacin, it could be an important adjunctive therapy. As such, more study in this area is warranted.

Both the TC and TAG analyses had a moderate amount of statistical heterogeneity, which is not surprising given the variety of garlic preparations used and the diversity of study designs being employed. We were not able to discern noticeable characteristic differences between the outlier studies and the other studies in our analyses. The results of several subgroup and sensitivity analyses warrant discussion. First, the effects of garlic on TC and TAG concentrations appear to be time dependent. Studies lasting greater than 12 weeks tended to have greater effects than those of shorter duration. Garlic powder formulations were superior to other formulations (garlic oil and aged extracts) in terms of reducing TC and TAG but a large constituency of the garlic powder studies used the Kwai ${ }^{\circledR}$ brand. We found that the Kwai ${ }^{\circledR}$ brand provided more robust effects than other brands. We cannot discern from this meta-analysis whether it the garlic powder formulation or some type of quality control or manufacturing feature of $\mathrm{Kwai}{ }^{\circledR}$ specifically that is responsible for this difference. Finally, studies employing dietary modification to both the garlic and placebo groups showed markedly attenuated effects with garlic $v$. studies that utilised garlic or placebo with no such dietary modification. Diet modification was considered to be either dietary counselling or mandatory diet restrictions. The TAG levels were only reduced by $0.03 \mathrm{mmol} / \mathrm{l}$ with dietary control relative to placebo (although not significantly) compared with reductions of $0.18 \mathrm{mmol} / \mathrm{l}$ in studies without diet control. It is possible that garlic could be reducing TC and TAG by blocking the absorption of dietary cholesterol and fatty acids and the use of dietary modification attenuates the impact of this blockade. This subgroup did, however, have a small but significant increase in HDL, arguing against this theory. Other mechanisms that have been proposed include reducing the activity of 3-hydroxy-3-methylglutaryl coenzyme A reductase and increased bile acid excretion ${ }^{(5,13)}$. Nonetheless, this discrepancy shows that garlic supplementation may not be appropriate for patients committed to improving their diet, but may be helpful for those who are not compliant with low-cholesterol diets. Randomised, controlled trials could better establish this observation.

There are limitations to the present study. First, while we only included double-blind studies in an attempt to increase the internal validity of the present results, many studies did not describe how patients were blinded. While in many types of studies it may be adequate to assume proper blinding even when not described, this is not possible with a preparation such as garlic as its scent may be difficult to mask. Some studies did report the use of placebo tablets sprayed with a small amount of garlic in order to prevent unblinding but many others did not. There is a possibility that studies of inadequate blinding were included. None of the studies in our analysis used raw, unprocessed garlic, as blinding would be difficult if not impossible. Second, there are inherent limitations in meta-analysis in that the 


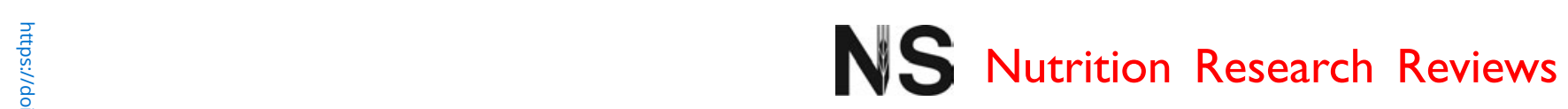

Table 3. Subgroup and sensitivity analyses results (Effect sizes and $95 \%$ confidence intervals)

\begin{tabular}{|c|c|c|c|c|c|c|c|c|c|c|c|c|}
\hline & \multicolumn{3}{|c|}{$\mathrm{TC}$} & \multicolumn{3}{|c|}{ LDL } & \multicolumn{3}{|c|}{$\mathrm{HDL}$} & \multicolumn{3}{|c|}{ TAG } \\
\hline & $\begin{array}{c}\text { Effect } \\
\text { size } \\
(\mathrm{mmol} / \mathrm{l})\end{array}$ & $\begin{array}{l}95 \% \mathrm{Cl} \\
(\mathrm{mmol} / \mathrm{l})\end{array}$ & $\begin{array}{l}I^{2} \\
(\%)\end{array}$ & $\begin{array}{c}\text { Effect } \\
\text { size } \\
(\mathrm{mmol} / \mathrm{l})\end{array}$ & $\begin{array}{l}95 \% \mathrm{Cl} \\
(\mathrm{mmol} / \mathrm{l})\end{array}$ & $\begin{array}{l}I^{2} \\
(\%)\end{array}$ & $\begin{array}{c}\text { Effect } \\
\text { size } \\
(\mathrm{mmol} / \mathrm{l})\end{array}$ & $\begin{array}{l}95 \% \mathrm{Cl} \\
(\mathrm{mmol} / \mathrm{l})\end{array}$ & $\begin{array}{l}I^{2} \\
(\%)\end{array}$ & $\begin{array}{c}\text { Effect } \\
\text { size } \\
(\mathrm{mmol} / \mathrm{l})\end{array}$ & $\begin{array}{l}95 \% \mathrm{Cl} \\
(\mathrm{mmol} / \mathrm{l})\end{array}$ & $\begin{array}{l}I^{2} \\
(\%)\end{array}$ \\
\hline \multicolumn{13}{|l|}{ Jadad score } \\
\hline $0-2$ & -0.20 & $-0.46,0.06$ & 30 & -0.05 & $-0.22,0.32$ & * & 0.12 & $-0.07,0.32$ & 76 & -0.32 & $-0.55,-0.09$ & 0 \\
\hline $3-5$ & -0.18 & $-0.33,-0.04$ & 67 & -0.07 & $-0.17,0.03$ & 29 & 0.02 & $-0.01,0.05$ & 0 & -0.09 & $-0.17,-0.00$ & 27 \\
\hline \multicolumn{13}{|l|}{ Duration (weeks) } \\
\hline $0-12$ & -0.07 & $-0.19,0.05$ & 15 & -0.03 & $-0.13,0.08$ & 0 & 0.02 & $-0.01,0.05$ & 9 & -0.06 & $-0.15,0.02$ & 0 \\
\hline$>12$ & -0.30 & $-0.53,0.07$ & 79 & -0.09 & $-0.26,0.08$ & 50 & 0.03 & $-0.02,0.09$ & 18 & -0.17 & $-0.33,-0.01$ & 52 \\
\hline \multicolumn{13}{|l|}{ Type } \\
\hline Garlic powder & -0.31 & $-0.51,-0.11$ & 71 & -0.04 & $-0.16,0.08$ & 10 & 0.00 & $-0.03,0.04$ & 12 & -0.11 & $-0.23,0.02$ & 42 \\
\hline Other & -0.05 & $-0.18,0.08$ & 25 & -0.07 & $-0.21,0.07$ & 40 & 0.05 & $0.01,0.09$ & 0 & -0.11 & $-0.21,-0.01$ & 3 \\
\hline \multicolumn{13}{|l|}{ Brand } \\
\hline $\mathrm{Kwai}^{\circledR}$ & -0.30 & $-0.52,-0.08$ & 76 & -0.01 & $-0.12,0.11$ & 0 & 0.03 & $-0.01,0.07$ & 0 & -0.16 & $-0.25,-0.06$ & 0 \\
\hline Not Kwai ${ }^{\circledR}$ & -0.09 & $-0.22,0.04$ & 26 & -0.09 & $-0.23,0.05$ & 44 & 0.03 & $-0.01,0.08$ & 40 & -0.04 & $-0.18,0.09$ & 41 \\
\hline \multicolumn{13}{|l|}{ Baseline TC } \\
\hline $\begin{aligned}> & 6.47 \mathrm{mmol} / \mathrm{l} \\
& (250 \mathrm{mg} / \mathrm{dl} ; 2500 \mathrm{mg} / \mathrm{l})\end{aligned}$ & -0.24 & $-0.44,-0.04$ & 75 & -0.02 & $-0.12,0.07$ & 0 & 0.02 & $-0.03,0.06$ & 43 & $-0 \cdot 10$ & $-0.23,0.03$ & 47 \\
\hline$\leq 6.47 \mathrm{mmol} / \mathrm{l}$ & -0.13 & $-0.27,0.01$ & 24 & -0.11 & $-0.28,0.05$ & 42 & 0.04 & $0.00,0.08$ & 0 & -0.11 & $-0.21,-0.01$ & 0 \\
\hline \multicolumn{13}{|l|}{ Baseline TAG } \\
\hline $\begin{array}{l}>1.69 \mathrm{mmol} / \mathrm{l} \\
(150 \mathrm{mg} / \mathrm{dl} ; 1500 \mathrm{mg} / \mathrm{l})\end{array}$ & -0.29 & $-0.52,-0.06$ & 77 & $-0 \cdot 11$ & $-0.29,0.07$ & 59 & 0.03 & $-0.03,0.08$ & 51 & $-0 \cdot 10$ & $-0.27,0.7$ & 53 \\
\hline$\leq 1.69 \mathrm{mmol} / \mathrm{l}$ & -0.05 & $-0.16,0.05$ & 0 & -0.02 & $-0.13,0.08$ & 0 & 0.03 & $-0.01,0.07$ & 0 & -0.09 & $-0.17,-0.01$ & 0 \\
\hline \multicolumn{13}{|l|}{ Diet control† } \\
\hline Yes & -0.09 & $-0.19,0.01$ & 4 & -0.08 & $-0.21,0.05$ & 47 & 0.00 & $-0.03,0.03$ & 0 & -0.03 & $-0.14,0.09$ & 14 \\
\hline No & -0.33 & $-0.59,-0.07$ & 77 & -0.03 & $-0.17,0.12$ & 0 & 0.06 & $0.02,0 \cdot 10$ & 1 & -0.18 & $-0.29,-0.07$ & 31 \\
\hline
\end{tabular}

TC, total cholesterol.

* The calculation could not be made due to the number of studies in the analysis $(n 2)$.

† Diet control indicates either diet counselling used or diet implemented during study. 
combining of heterogeneous studies limits validity. This may be particularly true for meta-analyses of garlic, as the wide variety of garlic preparations used, the different baseline risks and the different study procedures employed could increase the chances of seeing heterogeneous effects. However, we did employ subgroup analyses to probe for potential sources of heterogeneity.

\section{Conclusion}

Garlic reduces TC to a modest extent, an effect driven mostly by the modest reductions in TAG, without appreciable LDL lowering or HDL elevation. Patients taking Kwai ${ }^{\circledR}$ brand garlic, without dietary modification or counselling, appear to have greater lowering of TAG. Future studies should be conducted evaluating the impact of adjunctive garlic therapy with fibrates or statins on TAG concentrations.

\section{Acknowledgements}

K. M. R. was responsible for study design, data collection, statistical analysis and writing of the manuscript. R. T. was responsible for data collection. C. M. W. was responsible for preparation of the manuscript. C. I. C. was responsible for study design, statistical analysis and writing of the manuscript.

The authors of this manuscript have no conflicts of interest, financial or other, to disclose.

\section{References}

1. Grundy SM, Cleeman JI, Merz MB, et al. (2004) Implications of recent clinical trials for the National Cholesterol Education Program Adult Treatment Panel III guidelines. Circulation 110, 227-239.

2. Stevinson C, Pittler MH \& Ernst E (2000) Garlic for treating hypercholesterolemia. Ann Intern Med 133, 420-429.

3. Ackermann RT, Mulrow CD, Ramirez G, et al. (2001) Garlic shows promise for improving some cardiovascular risk factors. Arch Intern Med 161, 813-824.

4. Silagy C \& Neil A (1994) Garlic as a lipid lowering agent - a meta-analysis. J R Coll Physicians Lond 28, 39-45.

5. Warshafsky S, Kamer RS \& Sivak SL (1993) Effect of garlic on total serum cholesterol a meta-analysis. Ann Intern Med 119, 599-605.

6. Kris-Etherton PM \& Dietschy J (1997) Design criteria for studies examining individual fatty acid effects on cardiovascular disease risk factors: human and animal studies. Am J Clin Nutr 65, S1590-S1596.

7. Jadad AR, Moore A, Carroll D, et al. (1996) Assessing the quality of reports of randomized clinical trials: is blinding necessary? Controlled Clin Trials 17, 1-12.

8. Follmann D, Elliott P, Suh I, et al. (1992) Variance imputation for overviews of clinical trials with continuous response. J Clin Epidemiol 45, 769-773.

9. Adler AJ \& Holub BJ (1997) Effect of garlic and fishoil supplementation on serum lipid and lipoprotein concentrations in hypercholesterolemic men. Am J Clin Nutr 65, 445-450.

10. Auer W, Eiber A, Hertkorn E, et al. (1990) Hypertension and hyperlipidaemia: garlic helps in mild cases. Br J Clin Pract Suppl 69, 3-6.
11. Bordia A (1981) Effect of garlic on blood lipids in patients with coronary heart disease. Am J Clin Nutr 34, 2100-2103.

12. Budoff MJ, Takasu J, Flores FR, et al. (2004) Inhibiting progression of coronary calcification using aged garlic extract in patients receiving statin therapy: a preliminary study. Prev Med 39, 985-991.

13. Isaacsohn JL, Moser M, Stein EA, et al. (1998) Garlic powder and plasma lipids and lipoproteins. A multicenter, randomized, placebo-controlled trial. Arch Intern Med 158, 1189-1194.

14. Jain AK, Vargas R, Gotzkowsky S, et al. (1993) Can garlic reduce levels of serum lipids? A controlled clinical study. Am J Med 94, 632-635.

15. Kannar D, Wattanapenpaiboon N, Savige GS, et al. (2001) Hypocholersterolemic effect of an enteric-coated garlic supplement. J Am Coll Nutr 20, 225-231.

16. Kiesewetter H, Jung F, Jung EM, et al. (1993) Effects of garlic coated tablets in peripheral arterial occlusive disease. Clin Investig 71, 383-386.

17. Macan H, Uykimpang R, Alconcel M, et al. (2006) Aged garlic extract may be safe for patients on warfarin therapy. J Nutr 136, 793S-795S.

18. Mader FH (1990) Treatment of hyperlipidaemia with garlicpowder tablets. Evidence from the German Association of General Practitioners' multicentric placebo-controlled double-blind study. Arzneimittelforschung 40, 1111-1116.

19. McCrindle BW, Helden E \& Conner WT (1998) Garlic extract therapy in children with hypercholesterolemia. Arch Pediatr Adolesc Med 152, 1089-1094.

20. Neil HAW, Silagy CA, Lancaster T, et al. (1996) Garlic powder in the treatment of moderate hyperlipidaemia: a controlled trial and meta-analysis. $J$ R Coll Physicians Lond 30, 329-334.

21. Peleg A, Hershcovici T, Lipa R, et al. (2003) Effect of garlic on lipid profile and psychopathologic parameters in people with mild to moderate hypercholesterolemia. Isr Med Assoc J 5, 637-640.

22. Rahmani M, Tabari AK, Niaki MRK, et al. (1999) Effect of dried garlic supplementation on blood lipids in mild and moderate hypercholesterolemic patients. Arch Iran Med 2, 19-23.

23. Rotzsch W, Richter V, Rassoul F, et al. (1992) Postprandial lipeaemia under treatment with Allium sativum. Controlled double-blind study in healthy volunteers with reduced $\mathrm{HDL}_{2^{-}}$ cholesterol levels. Arzneimittelforschung 42, 1223-1227.

24. Santos OSDA \& Grünwald J (1993) Effect of garlic powder tablets on blood lipids and blood pressure - a six month placebo controlled, double blind study. Br J Clin Res 4, 37-44.

25. Saradeth T, Seidl S, Resch KL, et al. (1994) Does garlic alter the lipid pattern in normal volunteers? Phytomedicine 1, $183-185$.

26. Satitvipawee T, Rawdaree P, Indrabhakti S, et al. (2003) No effect of garlic extract supplement on serum lipid levels in hypercholesterolemic subjects. J Med Assoc Thai 86, $750-757$.

27. Superko HR \& Krauss RM (2000) Garlic powder, effect on plasma lipids, postprandial lipemia, low-density lipoprotein particle size, high-density lipoprotein subclass distribution and lipoprotein(a). J Am Coll Cardiol 35, 321-326.

28. Vorberg G \& Schneider B (1990) Therapy with garlic; results of a placebo-controlled, double blind study. Br J Clin Pract Suppl 69, 7-11.

29. Zhang XH, Lowe D, Giles P, et al. (2000) A randomized trial of the effects of garlic oil upon coronary heart disease risk factors in trained male runners. Blood Coagul Fibrinolysis 11, 67-74. 
30. Zhang XH, Lowe D, Giles P, et al. (2001) Gender may affect the action of garlic oil on plasma cholesterol and glucose levels of normal subjects. J Nutr 131, 1471-1478.

31. Phelps S \& Harris WS (1993) Garlic supplementation and lipoprotein oxidation susceptibility. Lipids 28, 475-477.

32. Berthold HK, Sudhop T \& Bergmann KV (1998) Effect of a garlic oil preparation on serum lipoproteins and cholesterol metabolism. A randomized controlled trial. JAMA 279, 1900-1902.

33. Simons LA, Balasubramaniam S, Konigsmark MV, et al. (1994) On the effect of garlic on plasma lipids and lipoproteins in mild hypercholesterolaemia. Atherosclerosis 113, 219-225.

34. Steiner M, Khan AH, Holbert D, et al. (1996) A double-blind crossover study in moderately hypercholesterolemic men that compared the effect of aged garlic extract and placebo administration on blood lipids. Am J Clin Nutr 64, 866-870.

35. Tanamai J, Veeramanomai S \& Indrakosas N (2004) The efficacy of cholesterol-lowering action and side effects of garlic enteric coated tablets in man. J Med Assoc Thai 87, $1156-1161$.

36. Williams MJ, Sutherland WH, McCormick MP, et al. (2005) Aged garlic extract improves endothelial function in men with coronary artery disease. Phytother Res 19, 314-319.

37. Plengvidhya C, Sitprija S, Chinayon S, et al. (1988) Effects of spray dried garlic preparation on primary hyperlipoproteinemia. J Med Assoc Thai 71, 248-252.

38. Bordia A, Verma SK \& Srivastava KC (1998) Effect of garlic (Allium sativum) on blood lipids, blood sugar, fibrinogen and fibrinolytic activity in patients with coronary artery disease. Prostaglandins Leukot Essent Fatty Acids 58, 257-263.

39. Lau BHS, Lam F \& Wang-Cheng R (1987) Effect of an odormodified garlic preparation on blood lipids. Nutr Res 7 , 139-149.

40. Brosche T, Platt D \& Dorner H (1990) The effect of a garlic preparation on the composition of plasma lipoproteins and erythrocyte membranes in geriatric subjects. Br J Clin Pract Suppl 69, 12-19.

41. Zimmermann W \& Zimmerman B (1990) Reduction in elevated blood lipids in hospitalized patients by a standardised garlic preparation. Br J Clin Pract Suppl 69, 20-23.

42. Santos OSDA \& Johns RA (1995) Effects of garlic powder and garlic oil preparations on blood lipids, blood pressure and well being. Br J Clin Res 6, 91-100.

43. Ziaei S, Hantoshzadeh S, Rezasoltani R, et al. (2001) The effect of garlic tablet on plasma lipids and platelet aggregation in nulliparous pregnants at high risk of preeclampsia. Eur J Obstet Gynecol Reprod Biol 99, 201-206.

44. Schmidt U (1991) The lipid-lowering effects of garlic powder tablets. A comparative study between a garlic powder preparation and bezafibrate (article in German). Med Welt 42, 7 Suppl. A, 6-7.

45. Chernyad'eva IF, Shil'nikova SV, Rogoza AN, et al. (2003) Dynamics of interrelationships between the content of lipoprotein particles, fibrinogen, and leukocyte count in the plasma from patients with coronary heart disease treated with Kwai ${ }^{\circledR}$. Bull Exp Biol Med 135, 436-439.

46. Kojuri J, Vosoughi AR \& Akrami M (2007) Effects of Anethum graveolens and garlic on lipid profile in hyperlipidemic patients. Lipids Health Dis 6, 5.

47. Gardner CD, Lawson LD, Block E, et al. (2007) Effect of raw garlic vs commercial garlic supplements on plasma lipid concentrations in adults with moderate hypercholesterolemia. Arch Intern Med 167, 146-153.

48. Ashraf R, Aamir R, Shaikh AR, et al. (2005) Effects of garlic on dyslipidemia in patients with type 2 diabetes mellitus. $J$ Ayub Med Coll Abbottabad 17, 60-64.

49. Gardner CD, Chatterjee LM \& Carlson JJ (2001) The effect of a garlic preparation on plasma lipid levels in moderately hypercholesterolemic adults. Atherosclerosis 154, 213-220.

50. Lash JP, Cardoso LR, Mesler PM, et al. (1998) The effect of garlic on hypercholesrolemia in renal transplant patients. Transplant Proc 30, 189-191.

51. Van Doorn MBA, Santo SME, Meijer P, et al. (2006) Effect of garlic powder on C-reactive protein and plasma lipids in overweight and smoking subjects. Am J Clin Nutr 84, 1324-1329.

52. Zhang L, Gail MH, Wang Y, et al. (2006) A randomized factorial study of the effects of long-term garlic and micronutrient supplementation and of 2-weeks antibiotic treatment for Helicobacter pylori infection on serum cholesterol and lipoproteins. Am J Clin Nutr 84, 912-919.

53. Turner B, Mølgaard C \& Marckmann P (2004) Effect of garlic (Allium sativum) powder tablets on serum lipids, blood pressure and arterial stiffness in normo-lipidaemic volunteers: a randomized, double-blind, placebo-controlled trial. Br J Nutr 92, 701-706.

54. Kiesewetter H, Jung F, Pindur G, et al. (1991) Effect of garlic on thrombocyte aggregation, microcirculation, and other risk factors. Int J Clin Pharmacol Ther Toxicol 29, 151-155.

55. Luley C, Lehmann-Leo W, Möller B, et al. (1986) Lack of efficacy of dried garlic in patients with hyperlipoproteinemia. Arzneimittelforschung 36, 766-768.

56. Jung F \& Kiesewetter H (1991) Influence of a lipid load on plasma lipids and capillary skin perfusion under garlic (article in German). Med Welt 42, 16-19.

57. Byrne DJ, Neil HAW, Vallance DT, et al. (1999) A pilot study of garlic consumption shows no significant effect on markers of oxidation or sub-fraction composition of low-density lipoprotein including lipoprotein(a) after allowance for noncompliance and the placebo effect. Clin Chim Acta 285, $21-33$.

58. Rosenson RS (2003) Rosuvastatin: a new inhibitor of HMG-coA reductase for the treatment of dyslipidemia. Expert Rev Cardiovasc Ther 1, 495-505.

59. White CM (1996) Treatment of hypercholesterolemia. In U. S. Pharmacist, July 1996, pp. 76-90. Lyndhwst, NJ: Jobson Medical Information LLC.

60. Holzgartner H, Schmidt U \& Kuhm U (1992) Comparison of the efficacy and tolerance of a garlic preparation $v$. bezafibrate. Drug Res 42, 1473-1477. 